\title{
Computational Study of 3d Metals and Their Influence on the Acidity of Methane $\mathrm{C}-\mathrm{H}$ Bonds
}

\author{
Christopher X. Zhou ${ }^{\circledR}$ and Thomas R. Cundari*(i)
}

Department of Chemistry, Center for Advanced Scientific Computing and Modeling (CASCaM), University of North Texas, 1155 Union Circle \#305070, Denton, Texas 76203-5017, United States

\section{Supporting Information}

ABSTRACT: $\operatorname{CCSD}(\mathrm{T})$ methods in conjunction with correlation consistent basis sets are used to predict the $\mathrm{p} K_{\mathrm{a}}$ for the deprotonation of methane in a $3 \mathrm{~d}$ metal ion adduct, $\left[\mathrm{M} \cdots \mathrm{CH}_{4}\right]^{+}(\mathrm{M}=\mathrm{Sc}-\mathrm{Cu})$, in dimethyl sulfoxide solvent, which is modeled by the SMD continuum solvent model. Results show that the coordination of methane to different $\mathrm{M}^{+}$ions has a substantial difference of $\sim 27 \mathrm{p} K_{\mathrm{a}}$ units, from most to least acidic, and increases the acidity of the methane $\mathrm{C}-\mathrm{H}$ bond from $\sim 8$ to $36 \mathrm{p} K_{\mathrm{a}}$ units. Furthermore, even with the omission of the more expensive quadruple and quintuple zeta basis sets in the prediction process, similar trends in $\mathrm{p} K_{\mathrm{a}}(\mathrm{C}-\mathrm{H})$ as a function of $3 \mathrm{~d}$ metal ions are exhibited. This research serves to illustrate the substantial effect that metal ion identity has on the acidity of a coordinated hydrocarbon and the utility that correlation consistent basis sets have in lowering the computational cost of modeling larger systems.

\section{INTRODUCTION}

Methane activation by organometallic catalysis remains a field of intense study, as it has significant technological implications. Methane is both plentiful, being the primary component of natural gas, and quite valuable. The process of methane conversion has a multitude of industrial applications, including the production of fuel that could serve as an alternative energy source to the conventional petroleum and coal. However, because of the thermodynamic strength of the $\mathrm{C}-\mathrm{H}$ bonds in methane and its very low acidity and basicity, it is difficult for methane to react readily.

Previous studies by Olah and co-workers ${ }^{1}$ have shown that methane only becomes reactive in superacidic systems, allowing for the protonation of methane as well as methane conversion. ${ }^{2}$ Similarly, the work of Streitwieser and Taylor demonstrated that methane is only deprotonated in superbasic systems. ${ }^{3}$ These works illustrate the significance that reaction conditions have on influencing methane activation. Superacid and superbasic systems still typically require forcing conditions and highly reactive reagents for methane conversion and, in most cases, are stoichiometric not catalytic.

Presently, the relationship between $\mathrm{p} K_{\mathrm{a}}$ of coordinated $\mathrm{C}-\mathrm{H}$ bonds and metal identity is an under researched area of organometallic chemistry. ${ }^{4}$ Whereas the acidic properties of a variety of organic carbon acids are reasonably well known, ${ }^{5}$ particularly in dimethyl sulfoxide (DMSO) solvent, there have been few studies concerning the acidity of $\mathrm{C}-\mathrm{H}$ bonds within transition-metal structures. Indeed, one rare study by Christman et al. investigates the enhancement of $\mathrm{p} K_{\mathrm{a}}$ for aromatic substrates by coordination to $\mathrm{Pd}(\mathrm{II}){ }^{4}$ In their experiments, these researchers estimated an increase in the acidity of arene $\mathrm{C}-\mathrm{H}$ bonds by 40 orders of magnitude or more upon coordination to cationic $\mathrm{Pd}(\mathrm{II})$ complexes.
In the present study, a Brønsted-Lowry acid/base reaction was examined, involving $3 \mathrm{~d}$ transition-metal methane adducts of the form of $\left[\mathrm{M} \cdots \mathrm{CH}_{4}\right]^{+}$and the solvent DMSO to gain more insights into the impact of the metal on the acid/base properties of aliphatic $\mathrm{C}-\mathrm{H}$ bonds in the coordination sphere of a $3 \mathrm{~d}$ metal ion. In the observed reaction (Figure 1), initially, the methane adduct is loosely coordinated to the $\mathrm{M}(\mathrm{I})$ ion (Figure 2). After the deprotonation of $\left[\mathrm{M} \cdots \mathrm{CH}_{4}\right]^{+}$, a shorter $\mathrm{M}-\mathrm{C}$ bond is formed along with a neutral methyl complex (Figure 3), which maintains $\mathrm{sp}^{3}$ hybridization at the carbon. In one study, Fallah and co-workers found that deprotonation of a methyl $\mathrm{C}-\mathrm{H}$ bond was a competing side reaction to methane functionalization. ${ }^{6}$ Thus, investigating the acid/base properties of aliphatic $\mathrm{C}-\mathrm{H}$ bonds of both hydrocarbon and hydrocarbyl complexes within the coordination sphere of a transition metal is important in catalyst design.

All $3 \mathrm{~d}$ metal ions were assumed to have a formal oxidation state of $1+$ in order to facilitate comparison among the various methane adducts. Highly accurate coupled cluster $(\operatorname{CCSD}(\mathrm{T}))$ calculations are performed to assess how metal identity impacts the intrinsic acid/base properties of a methane $\mathrm{C}-\mathrm{H}$ bond within the coordination sphere of a first-row transitionmetal ion (Sc through $\mathrm{Cu}$ ). Furthermore, $\operatorname{CCSD}(\mathrm{T})$ simulations, in conjunction with correlation consistent basis sets, can serve as a benchmark for future studies using more approximate density functional theory (DFT), which may be applied to larger, more experimentally relevant catalyst candidates.

Received: July 3, 2019

Accepted: November 6, 2019

Published: November 19, 2019 


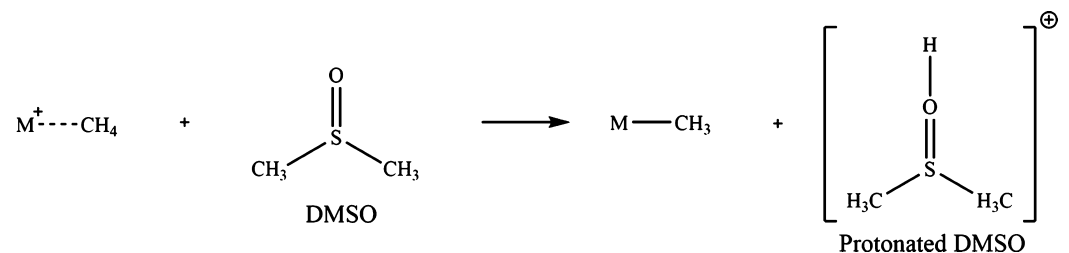

Figure 1. Acid/base reaction used to calculate methane $\mathrm{p} K_{\mathrm{a}}$ values: a $3 \mathrm{~d}$ metal methane adduct and DMSO results in a metallic methyl complex and protonated DMSO.

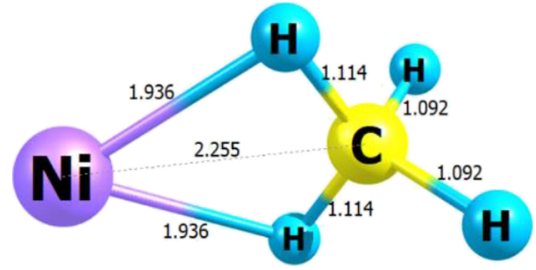

Figure 2. Nickel(I) methane adduct, a representative example of the methane adducts modeled in this research. B3LYP/6-31+G(d)optimized bond lengths are reported in angstroms.

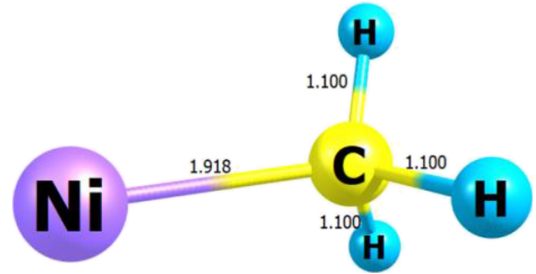

Figure 3. Nickel(I) methyl complex, a representative example of the methyl complexes modeled in this research. B3LYP/6-31+G(d)optimized bond lengths are reported in angstroms.

\section{RESULTS AND DISCUSSION}

$\mathrm{p} K_{\mathrm{a}}$ Values for 3d Metal(I) Methane Adducts. Given the simplicity of the present models, our main goal is to assess trends-rather than absolute values as a function of metal upon the Brønsted-Lowry acidity of a methane $\mathrm{C}-\mathrm{H}$ bond within the coordination sphere of a $3 \mathrm{~d}$ metal ion. Calculating the deprotonation of free methane with several complete basis set (CBS) extrapolation methods outlined in Computational Methods, it is less acidic than coordinated methane with an average $\mathrm{p} K_{\mathrm{a}}(\mathrm{C}-\mathrm{H})$ of 49.5 and a standard deviation of \pm 0.3 $\mathrm{p} K_{\mathrm{a}}$ units

The predicted ground-state multiplicities of the cationic $3 \mathrm{~d}$ metal methane adducts studied (Table 1) all agreed with

Table 1. Lowest Energy Multiplicities of Methane Adducts and Methyl Complexes Predicted from $\operatorname{CCSD}(\mathrm{T})$

Computations

$\begin{array}{lccccccccc} & \mathrm{Sc} & \mathrm{Ti} & \mathrm{V} & \mathrm{Cr} & \mathrm{Mn} & \mathrm{Fe} & \mathrm{Co} & \mathrm{Ni} & \mathrm{Cu} \\ {\left[\mathrm{M} \cdots \mathrm{CH}_{4}\right]^{+} \text {multiplicity }} & 1 & 4 & 5 & 4 & 7 & 6 & 3 & 2 & 1 \\ \mathrm{M}-\mathrm{CH}_{3} \text { multiplicity } & 1 & 4 & 5 & 6 & 7 & 6 & 3 & 2 & 1\end{array}$

experimental data reported in the National Institute of Standards and Technology (NIST) database for the "naked" metal monocations, except that of $\mathrm{Cr}(\mathrm{I})$, where single point $\operatorname{CCSD}(\mathrm{T})$ calculations predicted that $\left[\mathrm{Cr}(\mathrm{I}) \cdots \mathrm{CH}_{4}\right]^{+}$was a quartet ground state, but the NIST database suggested that the naked chromium cation should be a sextet. ${ }^{\text {. }}$ Likewise, the predicted multiplicities of the studied methyl complexes also agreed with the findings of Rinaldo et al. and McKee., ${ }^{8,9}$

In Table 2, the average estimated $\mathrm{p} K_{\mathrm{a}}$ of extrapolation methods is displayed along with the standard deviation in $\mathrm{p} K_{\mathrm{a}}$ values for each respective metal. Figure 4 shows that the $\mathrm{p} K_{\mathrm{a}}(\mathrm{C}-\mathrm{H})$ values as a function of the $3 \mathrm{~d}$ transition metals follow a trend, in which the acidity rises and falls twice, peaking at $\mathrm{Ti}^{+}$and $\mathrm{Mn}^{+}$.

Initially, the basis sets cc-pVDZ, cc-pVTZ, cc-pVQZ, and ccpV5Z were utilized in calculating single point energies. However, as the study progressed, it became apparent that the quintuple zeta basis set was not critical to determine accurate $\mathrm{pK}_{\mathrm{a}}(\mathrm{C}-\mathrm{H})$ estimates, as all extrapolation schemes yielded values within $\pm 2.1 \mathrm{p} K_{\mathrm{a}}$ units (Table 2). Because the deviation in predicted $\mathrm{p} K_{\mathrm{a}}$ values is quite small (Table 3 ), one could argue that the quadruple zeta basis set may also be unnecessary in approximating $\mathrm{p} K_{\mathrm{a}}$ values. Figure 4 further implies that the least expensive $\mathrm{DZ}$ and TZ basis sets show the same trends as the CBS extrapolations as well as the more expensive $\mathrm{QZ}$ and $5 \mathrm{Z}$ basis sets. Only utilizing the cc-pVDZ and cc-pVTZ basis sets, which are less computationally expensive, would enable larger organometallic complexes to be studied as well.

\section{CONCLUSIONS}

The goal of this study was to examine the effect metallic identity has on the acidity of a coordinated aliphatic $\mathrm{C}-\mathrm{H}$ bond using highly accurate $\operatorname{CCSD}(\mathrm{T})$ simulations in conjunction with correlation consistent basis sets and several CBS extrapolation techniques. It is clear from the present research that there is a very noticeable impact of the metal ion, as the highest and lowest $\mathrm{p} K_{\mathrm{a}}$ values differ by $\sim 27 \mathrm{p} K_{\mathrm{a}}$ units (Table 2). Furthermore, coordination of methane to the $3 \mathrm{~d}$ metal ion results in a dramatic increase in acidity as compared to that of free methane, ranging from $\sim 8$ to $36 \mathrm{p} K_{\mathrm{a}}$ units.

It was observed that less expensive basis sets may be utilized to obtain an accurate estimate of acidic properties (cc-pVTZ and cc-pVQZ) or reproduce trends as a function of metal (cc-

Table 2. Average and Standard Deviation of Methane Adduct $\mathrm{p} K_{\mathrm{a}}(\mathrm{C}-\mathrm{H})$ Values for Each Metal ${ }^{a}$

$\begin{array}{lrrrrrrrr} & \mathrm{Sc} & \mathrm{Ti} & \mathrm{V} & \mathrm{Cr} & \mathrm{Mn} & \mathrm{Fe} & \mathrm{Co} & \mathrm{Ni} \\ \mathrm{p} K_{\mathrm{a}} \text { average } & 31.1 & 39.4 & 34.2 & 28.6 & 41.4 & 36.3 & 26.7 & 14.0 \\ \mathrm{p} K_{\mathrm{a}} \text { standard dev. } & 1.0 & 1.1 & 1.0 & 1.0 & 0.9 & 0.8 & 2.1 & 1.9\end{array}$

${ }^{a}$ Averages and standard deviations were calculated with the values obtained from the extrapolation methods of each respective metal, excluding the $\mathrm{DZ}, \mathrm{TZ}, \mathrm{QZ}$, and $5 \mathrm{Z}$ values obtained from the cc-pVXZ energies. 


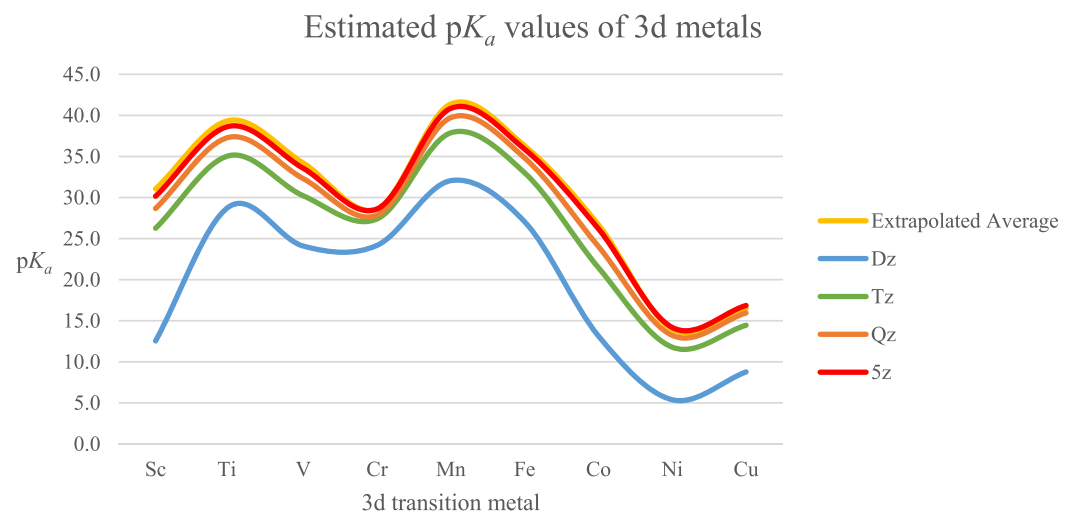

Figure 4. Bactrian camel trend exhibited by the $\mathrm{p} K_{\mathrm{a}}$ values of $3 \mathrm{~d}$ transition metals using $\operatorname{CCSD}(\mathrm{T})$ methods and correlation consistent basis sets (cc-pVXZ for $\mathrm{X}=2$ (DZ), $3(\mathrm{TZ}), 4(\mathrm{QZ})$, and $5(5 \mathrm{Z})$ ) at the B3LYP/6-31+G(d)-optimized geometries.

Table 3. Average and Standard Deviation of Methane Adduct $\mathrm{p} K_{\mathrm{a}}(\mathrm{C}-\mathrm{H})$ Values of Each Metal Utilizing Only Double and Triple Zeta Basis Set Extrapolation Methods

$\begin{array}{lrrrrrrrrrr} & \mathrm{Sc} & \mathrm{Ti} & \mathrm{V} & \mathrm{Cr} & \mathrm{Mn} & \mathrm{Fe} & \mathrm{Co} & \mathrm{Ni} & \mathrm{Cu} \\ \mathrm{p} K_{\mathrm{a}} \text { average } & 31.6 & 37.5 & 32.6 & 28.5 & 40.1 & 35.3 & 24.7 & 14.3 & 16.6 \\ \mathrm{p} K_{\mathrm{a}} \text { standard dev. } & 0.7 & 0.3 & 0.3 & 0.2 & 0.3 & 0.3 & 0.4 & 0.3 & 0.3\end{array}$

pVDZ). Employing just the cc-pVDZ and cc-pVTZ basis sets (Table 3 ), the resultant $\mathrm{p} K_{\mathrm{a}}$ values vary only slightly when compared to those that also utilize the cc-pVQZ and cc-pV5Z basis sets (Table 2). This is an important point to consider for further research, especially when dealing with larger metal complexes. Future studies could be worthwhile in investigating whether similar trends exist in more complex systems, $\mathrm{p} K_{\mathrm{a}}$ values other than DMSO, or complexes with more realistic ligands. Furthermore, $\operatorname{CCSD}(\mathrm{T})$ simulations, in conjunction with correlation consistent basis sets, can serve as a benchmark for future studies using more approximate DFT, which can be applied to larger, more experimentally relevant catalyst candidates. Another intriguing result of this research is the fact that $\mathrm{p} K_{\mathrm{a}}$ correlates surprisingly well not just with metal ion identity but also with $\mathrm{C}-\mathrm{H}$ bond lengths and vibrational frequencies (see the Supporting Information), which appears to be an additional point of interest for further investigation. Ultimately, while this study has made it clearer the impact that $3 \mathrm{~d}$ metals have on the $\mathrm{p} K_{\mathrm{a}}(\mathrm{C}-\mathrm{H})$, there remains much to be uncovered about what other chemical effects impact acidity, for example, the ligand environment as well as "outer sphere" effects such as hydrogen bonding, electrostatic and dispersion forces, and so forth.

Computational Methods. Geometry optimizations were performed with the Gaussian09 software package using the B3LYP/6-31+G(d) level of theory. ${ }^{10}$ Single point energies were calculated with the Gaussian 16 software package using the $\operatorname{UCCSD}(\mathrm{T})$ technique and the following basis sets: ccpVDZ, cc-pVTZ, cc-pVQZ, and cc-pV5Z. ${ }^{11}$ Tests with restricted open-shell $\operatorname{CCSD}(\mathrm{T})$ calculations for the titanium and nickel complexes did not appreciably change the predicted $\mathrm{p} K_{\mathrm{a}}(\mathrm{C}-\mathrm{H})$ values nor did the computed $\left\langle S^{2}\right\rangle$ expectation values suggest issues from spin contamination. Likewise, tests with larger, more expensive core-valence correlation treatments (the "Full" and "FreezeInnerNobleGasCore" options in Gaussian16) and consideration of scalar relativistic effects (Douglas-Kroll-Hess second-order scalar relativistic calculation) changed estimated $\mathrm{p} K_{\mathrm{a}}(\mathrm{C}-\mathrm{H})$ values by less than $1 \mathrm{p} K_{\mathrm{a}}$ unit. Additionally, the use of augmented correlation consistent basis sets was tested on methane adducts of $\mathrm{Sc}^{+}, \mathrm{Ti}^{+}$, and $\mathrm{Ni}^{+}$, changing $\mathrm{p} K_{\mathrm{a}}$ estimates by only as much as $0.3 \mathrm{p} K_{\mathrm{a}}$ units.

The energies obtained from the $\operatorname{UCCSD}(T)$ technique paired with correlation consistent basis sets were used to extrapolate to the CBS limit by employing various extrapolation schemes gathered by Vasilyev: ${ }^{12}$ exponential (eq 1), ${ }^{13}$ power function (eq 2), ${ }^{14}$ mixed Gaussian (eq 3), ${ }^{15}$ eq 11 in the paper by Vasilyev ${ }^{9}$ (eq 4), ${ }^{16}$ three parameters (eq 5), ${ }^{13}$ two parameters with integer exponent 4 (eq 6), ${ }^{13}$ and two parameters with integer exponent 3 (eq 7). ${ }^{11}$ The extrapolations were applied with the following equations

$$
E_{\mathrm{CBS}}=\frac{E(\mathrm{DZ}) E(\mathrm{QZ})-E(\mathrm{TZ})^{2}}{E(\mathrm{DZ})-2 E(\mathrm{TZ})+E(\mathrm{QZ})}
$$

$\left\{\begin{array}{c}E(\mathrm{DZ})=E_{\mathrm{CBS}}+B \mathrm{e}^{-2 a} \\ E(\mathrm{TZ})=E_{\mathrm{CBS}}+B \mathrm{e}^{-3 a} \\ E(\mathrm{QZ})=E_{\mathrm{CBS}}+B \mathrm{e}^{-4 a} \\ \vdots \\ E(n)=E_{\mathrm{CBS}}+B \mathrm{e}^{-n \cdot \alpha}\end{array}\right.$

$C=\mathrm{e}^{n_{1}^{2}+n_{2}{ }^{2}+3 n_{3}}, \quad D=\mathrm{e}^{3 n_{1}+n_{2}{ }^{2}+n_{3}{ }^{2}}, \quad F=\mathrm{e}^{n_{1}^{2}+3 n_{2}+n_{3}^{2}}$

$E_{\text {CBS }}=\frac{C\left(\mathrm{e}^{n_{1}} E_{1}-\mathrm{e}^{n_{2}} E_{2}\right)+D\left(\mathrm{e}^{n_{2}} E_{2}-\mathrm{e}^{n_{3}} E_{3}\right)+F\left(\mathrm{e}^{n_{3}} E_{3}-\right.}{C\left(\mathrm{e}^{n_{1}}-\mathrm{e}^{n_{2}}\right)+D\left(\mathrm{e}^{n_{2}}-\mathrm{e}^{n_{3}}\right)+F\left(\mathrm{e}^{n_{3}}-\mathrm{e}^{n_{1}} \cdot\right.}$

$\left\{\begin{array}{c}E(\mathrm{DZ})=E_{\mathrm{CBS}}+B \cdot 2^{-\alpha} \\ E(\mathrm{TZ})=E_{\mathrm{CBS}}+B \cdot 3^{-\alpha} \\ E(\mathrm{QZ})=E_{\mathrm{CBS}}+B \cdot 4^{-\alpha} \\ \vdots \\ E(n)=E_{\mathrm{CBS}}+B \cdot n^{-\alpha}\end{array}\right.$ 


$$
\begin{aligned}
& G=\frac{E_{3}\left(n_{1}-n_{2}\right)\left(1+n_{1}+n_{2}\right)}{\left(1+2 n_{1}\right)^{6}\left(1+2 n_{2}\right)^{6}} \\
& +\frac{\frac{E_{1}\left(n_{2}-n_{3}\right)\left(1+n_{2}+n_{3}\right)}{\left(1+2 n_{2}\right)^{6}}+\frac{E_{2}\left(-n_{1}\left(1+n_{1}\right)+n_{3}+n_{3}^{2}\right)}{\left(1+2 n_{1}\right)^{6}}}{\left(1+2 n_{3}\right)^{6}} \\
& H=16\left(-n_{1}+n_{2}\right)\left(1+n_{1}+n_{2}\right)\left(n_{1}-n_{3}\right)\left(n_{2}-n_{3}\right) \\
& \left(1+n_{1}+n_{3}\right)\left(1+n_{2}+n_{3}\right) \\
& E_{\mathrm{CBS}} \\
& =\frac{-\left(G\left(1+2 n_{1}\right)^{6}\left(1+2 n_{2}\right)^{6}\left(1+2 n_{3}\right)^{6}\right.}{H\left(3+4 n_{1}\left(1+n_{1}\right)+4 n_{2}\left(1+n_{2}\right)+4 n_{3}\left(1+n_{3}\right)\right)} \\
& E_{C B S}=\frac{\frac{E_{2}}{\left(0.5+n_{1}\right)^{4}}-\frac{E_{1}}{\left(0.5+n_{2}\right)^{4}}}{\frac{1}{\left(0.5+n_{1}\right)^{4}}-\frac{1}{\left(0.5+n_{2}\right)^{4}}} \\
& E_{\mathrm{CBS}}=\frac{E_{1} n_{1}^{3}-E_{2} n_{2}{ }^{3}}{n_{1}{ }^{3}-n_{2}{ }^{3}}
\end{aligned}
$$

where $n_{x}$ represents the cardinal number of the $x$ th basis set used and $E_{x}$ denotes the electronic energy obtained from the $x$ th basis set used. Obtaining the electronic energies at the basis set limit, the Gibbs free energy correction of each respective structure (obtained from DFT geometry optimization and vibrational frequency calculation) was then applied to calculate the Gibbs free energy at the basis set limit $\left(G_{\mathrm{CBS}}\right)$. From the $G_{\mathrm{CBS}}$ free energies, the $\Delta G_{\mathrm{CBS}}$ of deprotonation was computed for each of the $3 \mathrm{~d}$ metals. In order to estimate the $\mathrm{p} K_{\mathrm{a}}$ of each metal, the following formula was used

$$
\mathrm{p} K_{\mathrm{a}} \text { calc. }=\frac{\Delta G_{\mathrm{CBS}}}{2.303 R T}
$$

to obtain an initial $\mathrm{p} K_{\mathrm{a}}$ value. A linear correction derived from the published work of Nazemi and Cundari ${ }^{17}$ was then applied to the $\mathrm{p} K_{\mathrm{a}}$ calc. to get the final estimated $\mathrm{p} K_{\mathrm{a}}$ of the methane adduct, $\left[\mathrm{M} \cdots \mathrm{CH}_{4}\right]^{+}(\mathrm{M}=\mathrm{Sc}-\mathrm{Cu})$.

$$
\mathrm{p} K_{\mathrm{a}} \text { est. }=1.0308 \mathrm{pK}_{\mathrm{a}} \text { calc. }-12.146
$$

\section{ASSOCIATED CONTENT}

\section{S Supporting Information}

The Supporting Information is available free of charge on the ACS Publications website at DOI: 10.1021/acsomega.9b02038.

$\operatorname{CCSD}(\mathrm{T})$ electronic energies computed with the various correlation consistent basis sets and analysis on the structural and vibrational properties of methane adducts, along with correlations between $\mathrm{p} K_{\mathrm{a}}$ and $\mathrm{C}-\mathrm{H}$ bond lengths/ $\mathrm{C}-\mathrm{H}$ vibrational frequencies (PDF)

Cartesian coordinates for the B3LYP/6-31+G(d) optimized geometries at which the $\operatorname{CCSD}(\mathrm{T})$ single point energies were evaluated (XYZ)

\section{AUTHOR INFORMATION}

\section{Corresponding Author}

*E-mail: t@unt.edu.

\section{ORCID}

Christopher X. Zhou: 0000-0002-7839-0817

Thomas R. Cundari: 0000-0003-1822-6473

Notes

The authors declare no competing financial interest.

\section{ACKNOWLEDGMENTS}

C.X.Z. would like to thank the Texas Academy of Mathematics and Science (TAMS) at the University of North Texas and the Honors College for a TAMS Summer Research Scholarship. The authors thank the National Science Foundation for their generous support through grant CHE-1464943 and their support for the UNT CASCaM HPC cluster via grant CHE1531468 .

\section{REFERENCES}

(1) Olah, G. A.; Schlosberg, R. H. Chemistry in Super Acids. I. Hydrogen Exchange and Polycondensation of Methane and Alkanes in $\mathrm{FSO}_{3} \mathrm{H}-\mathrm{SbF}_{5}$ ("Magic Acid") Solution. Protonation of Alkanes and the Intermediacy of CH5 and Related Hydrocarbon Ions. The High Chemical Reactivity of "Paraffins" in Ionic Solution Reactions. J. Am. Chem. Soc. 1968, 90, 2726-2727.

(2) Olah, G. A. Electrophilic Methane Conversion. Acc. Chem. Res. 1987, 20, 422-428.

(3) Streitwieser, A.; Taylor, D. R. Kinetic Acidity of Methane. J. Chem. Soc. D 1970, 19, 1248.

(4) Christman, W. E.; Morrow, T. J.; Arulsamy, N.; Hulley, E. B. Absolute Estimates of $\mathrm{Pd}^{\mathrm{II}}\left(\eta^{2}\right.$-Arene $) \mathrm{C}-\mathrm{H}$ Acidity. Organometallics 2018, 37, 2706-2715.

(5) https://www.chem.wisc.edu/areas/reich/pkatable/ (accessed June 17, 2019).

(6) Fallah, H.; Horng, F.; Cundari, T. R. Theoretical Study of Two Possible Side Reactions for Reductive Functionalization of 3d MetalMethyl Complexes by Hydroxide Ion: Deprotonation and MetalMethyl Bond Dissociation. Organometallics 2016, 35, 950-958.

(7) Suplee, C. Handbook of Basic Atomic Spectroscopic Data. https://www.nist.gov/pml/handbook-basic-atomic-spectroscopicdata (accessed June 24, 2019).

(8) Rinaldo, D.; Tian, L.; Harvey, J. N.; Friesner, R. A. Density Functional Localized Orbital Corrections for Transition Metals. J. Chem. Phys. 2008, 129, 164108.

(9) McKee, M. L. Ab Initio Study of the Interaction of Iron, Iron Cation and $\mathrm{HFe}$ with $\mathrm{H}, \mathrm{CH}, \mathrm{CH}_{2}, \mathrm{CH}_{3}$, and $\mathrm{C}_{5} \mathrm{H}_{5}$. J. Am. Chem. Soc. 1990, 112, 2601-2607.

(10) Frisch, M. J.; Trucks, G. W.; Schlegel, H. B.; Scuseria, G. E.; Robb, M. A.; Cheeseman, J. R.; Scalmani, V.; Barone, G.; Mennucci, B.; Petersson, G. A.; Nakatsuji, H.; Caricato, M.; Li, X.; Hratchian, H. P.; Izmaylov, A. F.; Bloino, J.; Zheng, G.; Sonnenberg, J. L.; Hada, M.; Ehara, M.; Toyota, K.; Fukuda, R.; Hasegawa, J.; Ishida, M.; Nakajima, T.; Honda, Y.; Kitao, O.; Nakai, H.; Vreven, T.; Montgomery, J. A., Jr.; Peralta, J. E.; Ogliaro, F.; Bearpark, M.; Heyd, J. J.; Brothers, E.; Kudin, K. N.; Staroverov, V. N.; Keith, T.; Kobayashi, R.; Normand, J.; Raghavachari, K.; Rendell, A.; Burant, J. C.; Iyengar, S. S.; Tomasi, J.; Cossi, M.; Rega, N.; Millam, J. M.; Klene, M.; Knox, J. E.; Cross, J. B.; Bakken, V.; Adamo, C.; Jaramillo, J.; Gomperts, R.; Stratmann, R. E.; Yazyev, O.; Austin, A. J.; Cammi, R.; Pomelli, C.; Ochterski, J. W.; Martin, R. L.; Morokuma, K.; Zakrzewski, V. G.; Voth, G. A.; Salvador, P.; Dannenberg, J. J.; Dapprich, S.; Daniels, A. D.; Farkas, O.; Foresman, J. B.; Ortiz, J. V.; Cioslowski, J.; Fox, D. J. Gaussian 09, Revision E.01; Gaussian, Inc.: Wallingford CT, 2013.

(11) Frisch, M. J.; Trucks, G. W.; Schlegel, H. B.; Scuseria, G. E.; Robb, M. A.; Cheeseman, J. R.; Scalmani, V.; Barone, G.; Mennucci, B.; Petersson, G. A.; Nakatsuji, H.; Caricato, M.; Li, X.; Hratchian, H. P.; Izmaylov, A. F.; Bloino, J.; Zheng, G.; Sonnenberg, J. L.; Hada, M.; Ehara, M.; Toyota, K.; Fukuda, R.; Hasegawa, J.; Ishida, M.; Nakajima, T.; Honda, Y.; Kitao, O.; Nakai, H.; Vreven, T.; Montgomery, J. A., Jr.; Peralta, J. E.; Ogliaro, F.; Bearpark, M.; Heyd, J. J.; Brothers, E.; Kudin, K. N.; Staroverov, V. N.; Keith, T.; Kobayashi, R.; Normand, J.; Raghavachari, K.; Rendell, A.; Burant, J. C.; Iyengar, S. S.; Tomasi, J.; Cossi, M.; Rega, N.; Millam, J. M.; Klene, M.; Knox, J. E.; Cross, J. B.; Bakken, V.; Adamo, C.; Jaramillo, J.; Gomperts, R.; Stratmann, R. E.; Yazyev, O.; Austin, A. J.; Cammi, R.; Pomelli, C.; Ochterski, J. W.; Martin, R. L.; Morokuma, K.; 
Zakrzewski, V. G.; Voth, G. A.; Salvador, P.; Dannenberg, J. J.; Dapprich, S.; Daniels, A. D.; Farkas, O.; Foresman, J. B.; Ortiz, J. V.; Cioslowski, J.; Fox, D. J. Gaussian 16, Revision A.03; Gaussian, Inc.: Wallingford CT, 2016.

(12) Vasilyev, V. Online Complete Basis Set Limit Extrapolation Calculator. Comput. Theor. Chem. 2017, 1115, 1-3.

(13) Halkier, A.; Helgaker, T.; Jørgensen, P.; Klopper, W.; Olsen, J. Basis-Set Convergence of the Energy in Molecular Hartree-Fock Calculations. Chem. Phys. Lett. 1999, 302, 437-446.

(14) Helgaker, T.; Klopper, W.; Koch, H.; Noga, J. Basis-Set Convergence of Correlated Calculations on Water. J. Chem. Phys. 1997, 106, 9639-9646.

(15) Peterson, K. A.; Woon, D. E.; Dunning, T. H. Benchmark Calculations with Correlated Molecular Wave Functions. IV. The Classical Barrier Height of the $\mathrm{H}+\mathrm{H}_{2} \rightarrow \mathrm{H}_{2}+\mathrm{H}$ Reaction. J. Chem. Phys. 1994, 100, 7410-7415.

(16) Martin, J. M. L. Ab Initio Total Atomization Energies of Small Molecules - towards the Basis Set Limit. Chem. Phys. Lett. 1996, $259,669-678$.

(17) Nazemi, A.; Cundari, T. R. Control of C-H Bond Activation by Mo-Oxo Complexes: pKa or Bond Dissociation Free Energy (BDFE)? Inorg. Chem. 2017, 56, 12319-12327. 